\title{
A Cluster of Cases of Acute Poststreptococcal Glomerulonephritis in a Family
}

\section{Asma Ferdousi* \\ Nazmul Ahsan \\ Mitra Datta}

Department of Pediatrics

Upazilla Health Complex, Anwara

Chittagong, Bangladesh.
*Correspondence to:

\section{Dr. Asma Ferdousi}

Junior Consultant

Department of Pediatrics

Upzilla Health Complex, Anwara

Chittagong, Bangladesh.

Mobile : +8801824825800

E-mail : aferdoushi71 gmail.com

\begin{abstract}
Acute post streptococcal glomerulonephritis (APSGN) remains a common cause of acute nephritis in children. Acute poststreptococcal glomerulonephritis usually occurs as sporadic cases, occasionally an unusually high incidence of acute nephritis has been recorded. In our country we need to recognize, document and analyze epidemic attacks of acute post streptococcal glomerulonephritis. Then we can plan for it's prevention. We have reported here a cluster of cases of APSGN prevailed in a family of a rural setting of southeast part of Bangladesh which was admitted in a subdistrict level hospital and also noticed that total admitted cases of APSGN in that hospital was more during the month of notification in comparison to other months but were not able to identify all the cases of APSGN prevailing in that area. Prophylactic antibiotic treatment is advisable in epidemic conditions and to household contacts of index cases in communities where the prevalence of the disease is high. It is expected that there are some cluster of cases of APSGN in different regions of our country during different period that is to be notified. Public awareness regarding prevention and early treatment of scabis is required.
\end{abstract}

Key words : Acute post streptococcal glomerulonephritis (APSGN); Epidemic; prevention; Acute nephritis.

\section{INTRODUCTION}

Acute glomerulonephritis (AGN) is a representative disease of acute nephritic syndrome.

Acute post streptococcal glomerulonephritis (APSGN) remains a common cause of acute nephritis in children. Approximately three quarters of cases are preceded by upper respiratory tract or skin infections.APSGN results from infection by nephritogenic streptococci. The latter are defined as organisms that are cultured from patients who develop APSGN.

APSGN is now known to follow infection by group A beta hemolytic streptococci. The $\mathrm{M}$ and $\mathrm{T}$ proteins in the bacterial wall have been used for characterizing streptococci, M types 1, 2, 4, 12, 18, 25, 49, 55, 57, and 60 may have nephritogenic potential. These may cause skin or throat infections, but specific M types, such as $49,55,57$, and 60 , are most commonly associated with skin infections. In addition, nontypeable group A streptococci are frequently isolated from the skin or throat of patients with glomerulonephritis, representing presumably unclassified nephritogenic strains ${ }^{1}$. The overall risk of developing acute poststreptococcal glomerulonephritis after infection by these nephritogenic strains is about $15 \%$. The risk of nephritis may also be related to the $\mathrm{M}$ type and the site of infection. The risk of developing nephritis infection by $\mathrm{M}$ type 49 is $5 \%$ if it is present in the throat. This risk increases to $25 \%$ if infection by the same organism in the skin is present. $11 \mathrm{~A}$ decline in the incidence of acute poststreptococcal glomerulonephritis in developed and developing countries has been reported over the last 2-3 decades. As many as $50 \%$ of cases may be subclinical; thus, the true incidence of the disease is unknown. 
Nevertheless, acute poststreptococcal glomerulonephritis continues to have a wide distribution as indicated by reports of the disease from all over the world. Because a high percentage of persons affected with acute poststreptococcal glomerulonephritis have mild disease and are asymptomatic (estimates of the ratio of asymptomatic to symptomatic patients vary from 2:1-3:1), the actual incidence of the disease is not known. Less-crowded living conditions may have contributed to the apparent decline in the incidence of acute poststreptococcal glomerulonephritis over the past few decades; however, other factors, including decreased prevalence or infectivity of the nephritogenic streptococci, may also have contributed to the decline. The recently observed increase in incidence is more difficult to explain.

Acute poststreptococcal glomerulonephritis usually occurs as sporadic cases, occasionally an unusually high incidence of acute nephritis has been recorded both in wide-spread epidemics and in focal outbreaks in small population units. Epidemic outbreaks have taken place in communities with densely populated dwellings that have poor hygienic conditions with a high incidence of malnutrition, anemia, and intestinal parasites. In certain regions, epidemics may occur in cyclical outbreaks every 5-7 years for unknown reasons. A strong seasonal variation is also noted; sporadic acute poststreptococcal glomerulonephritis following upper respiratory infection, pharyngitis, and tonsillitis is more common in winter and spring in temperate areas, whereas skin infections are commonly found to precede acute poststreptococcal glomerulonephritis in the more tropical and subtropical areas, with a peak incidence during summer and autumn.

In the study conducted by Streeton et al, it is recommended that mass use of penicillin may have had an effect in reducing the transmission of the nephritogenic strain of group A beta hemolytic streptococcus ${ }^{2}$.

Rodriguez-iturbe et al suggested that prophylactic antibiotic treatment is advisable in epidemic conditions and to household contacts of index cases in communities where the prevalence of the disease is high $^{3}$.

The protection of household contacts with Benzathin Penicillin is recommend by Berrios X because lower secondary attack rate has been observed in prophylaxis versus non protected groups ${ }^{4}$. In our country we need to recognize, document and analyze epidemic attacks of acute post streptococcal glomerulonephritis. Then we can plan for it's prevention.

\section{CASE REPORT}

$\mathrm{M}, \mathrm{S}$ and A are 3 sibs of a nonconsanguineous parent aged 11, 9 and 6 years respectively came from a rural setting of southeast part of Bangladesh ( Bairag Union of Anwara Upazilla of Chittagong district) to the skin OPD of a subdistrict level hospital (Anwara Upazilla Health Complex) with the complaints of itchy skin rash for 2-3 weeks, puffy face for 2-3 days and high coloured scanty urine for same duration. Here, $M$ is a male child and S and A are female child. All of them came with the same complaints successively at few days interval.
S came 1 day after $\mathrm{M}$ and A came 4 days after S. All of them were diagnosed as infected scabies and were referred to Pediatrics OPD on the day of visit. Subsequently they were admitted in Paediatrics Ward and were diagnosed as Acute Glomerulonephritis with infected scabies. M and A were found to be normotensive, $\mathrm{S}$ was found to be hypertensive. They had macroscopic hematuria. Urinanalysis showed RBC cast, different numbers of RBC and pus cells. ASO titre raised. Serum C3 low. Serum creatinine normal. USG of KUB and urine for $\mathrm{c} / \mathrm{s}$ reports were normal. They were treated as cases of post streptococcal glomerulonephritis and were discharged after improvement. Organisms could not be isolated from infected skin lesions. As infected scabis was present it was assumed that Streptococcus is the causative organism.Thereafter follow up done at 6 weeks and there were no RBC in the urine. At that time, serum $\mathrm{C} 3$ levels of $\mathrm{M}$ and $\mathrm{A}$ were normal. During next follow up at 3 month serum C3 level of $\mathrm{S}$ was also found normal. Some important clinical and lab parameters are shown in table I.

They have no such attack before, no family history of renal diseases, no visual or auditory complaint. During the month of reporting i.e. October,2010 the percentage of Acute Glomerulonephritis among total admitted patient was $2.17 \%$, whereas during the month of September and November it were $1.84 \%$ and $1.02 \%$ respectively.

Table I : Clinical and lab parameters of the three sibs

\begin{tabular}{lccc} 
Clinical and lab parameter & M & S & A \\
BP (mm of Hg) & $110 / 75$ & $120 / 80$ & $100 / 70$ \\
Macroscopic & & & \\
hematuria & Present & present & present \\
No. of RBC in urine per HPF & Plenty & $30-40$ & plenty \\
RBC cast in urine & Present & present & present \\
No. of pus cell in urine per HPF & $8-10$ & $7-8$ & $10-12$ \\
ASO titre (I.U) & $>400$ & $>400$ & $>400$ \\
Serum C3 level (gm/dl) & .56 & .82 & .57 \\
Serum creatinine level (mg/dl) & 1.1 & .7 & .6 \\
\hline
\end{tabular}

\section{DISCUSSION}

We have reported here a cluster of cases of APSGN prevailed in a family of a rural setting of southeast part of Bangladesh which was admitted in a subdistrict level hospital and also noticed that total admitted cases of APSGN in that hospital was more during the month of notification in comparison to other months but were not able to identify all the cases of APSGN prevailing in that area. Here organisms could not be isolated from the infected skin lesions. As infected scabis was present it was assumed that Streptococcus is the causative agent.

There are so many history of epidemics of acute PSGN where clusters of cases with less than 100 and some also with more than 100 cases. 58 cases of acute PSGN at North Queensland of Australia after skin infections on 1993 and cluster of cases after throat infection at Linköping of Sweden caused by S. pyogens, S. constellatus on 2005 are some examples ${ }^{5,6}$. 
Significant changes have occurred in its epidemiology. The disease is now rare in industrialized nations, but in the underprivileged world, the burden of poststreptococcal glomerulonephritis ranges between 9.5 and 28.5 new cases per 100,000 individuals per year ${ }^{3}$.

The long-term prognosis of PSGN in children has been the subject of many studies. The initial reports of natural history of PSGN in the first half of the 20th century indicated an excellent prognosis, but follow-up periods were relatively short. Subsequent studies gave conflicting results because abnormal urinary findings were as low as $3.5 \%$ and as high as $60 \%{ }^{7,8}$.

Prophylactic antibiotic treatment is advisable in epidemic conditions and to household contacts of index cases in communities where the prevalence of the disease is high.

Efficient and better funded public health system in some nations facilitates the recognition and early antibiotic treatment of streptococcal infections in index cases of PSGN. Underprivileged communities in less developed nations may have clusters of cases of APSGN that go unreported. There are some data reviewed, suggest that PSGN remains a significant health problem in underdeveloped countries.
Additional insight into the potential burden of PSGN in these nations may be gained from the evaluation of the incidence of the most severe cases of the disease in pediatric referral hospitals. Acute postinfectious glomerulonephritis is frequently the cause of severe acute renal failure (requiring dialysis and/or admission to pediatric intensive care units) in underdeveloped countries. The proportion of cases of acute renal failure that correspond to acute postinfectious glomerulonephritis of demonstrated or assumed poststreptococcal etiology is 13\% in New Delhi, $51.6 \%$ in Casablanca, $27 \%$ in Bombay, $19.2 \%$ in Lucknow, and $25 \%$ in Osun State, Nigeria ${ }^{9-13}$.

In our country we need to develop more efficient public health system to recognize epidemic attack due to APSGN and to reduce thereby by preventing and treating the cases properly.

\section{CONCLUSION}

It is expected that there are some cluster of cases of APSGN in different regions of our country during different period that is to be notified. Public awareness regarding prevention and early treatment of scabis is required.

\section{DISCLOSURE}

All the authors declared no competing interest.

\section{REFERENCES}

1. Nissenson AR, Baraff LJ, Fine RN, Knutson DW. Poststreptococcal acute glomerulonephritis: fact and controversy. Ann Intern Med. Jul 1979;91(1):76-86.

2. Streeton CL, Hanna JN, Messer RD. and Merianos A. An epidemic of acute post-streptococcal glomerulonephritis among Aboriginal children. Journal of Paediatrics and Child Health. 1995;31: 245-248.

3. Rodriguez-Iturb B. and Musser JM. The Current State of Poststreptococcal Glomerulonephritis. J Am Soc Nephrol. 2008; 19: 1855-1864.

4. Berríos, X. Epidemic outbreak of acute post streptococcal glomerulonephritis. Rev Chil Pediatr. 1990 ; 61(2):109-112.

5. Streeton CL, Hanna JN, Messer RD, Merianos A: An epidemic of acute post-streptococcal glomerulonephritis among Aboriginal children. J Paediatr Child Health. 1995; $31: 245-248$.

6. Almroth G, Lindell A, Aselius H, Sörén L, Svensson L, Hultman P, Eribe ER, Olsen I. Acute glomerulonephritis associated with Streptococcus pyogenes with concomitant spread of Streptococcus constellatus in four rural families. Ups J Med Sci. 2005; 110 : $217-231$.

7. Potter EV, Lipschultz SA, Abidh S, Poon-King T, Earle DP: Twelve to seventeen-year follow up of patients with acute poststreptococcal glomerulonephritis in Trinidad. N Engl J Med. 1982;307 : 725 -729.

8. Baldwin DS, Gluck MC, Schacht RG, Gallo G: The long-term course of poststreptococcal glomerulonephritis. Ann Intern Med. $1974 ; 80: 342-358$.

9. Srivastava RN, Bagga A, Moudgil A: Acute renal failure in north Indian children. Indian J Med. Res 1990;92: 404-408.

10. Bourquia A, Zaid D: Acute renal insufficiency in children: A retrospective study of 89 cases. Ann Pediatr (Paris).1993; 40: 603-608.

11. Kandoth PW, Agarwal GJ, Dharnidharka VR: Acute renal failure in children requiring dialysis therapy. Indian Pediatr.1994; 31 : 305-309.

12. Arora P, Kher V, Gupta A, Kohli HS, Gulati S, Rai PK, Kumar P, Sharma RK: Pattern of acute renal failure at a referral hospital. Indian Pediatr. 1994; 31: 1047-1053.

13. Olowu WA, Adelusola KA: Pediatric acute renal failure in southwestern Nigeria. Kidney Int. 2004;66: 1541-1548. 